\title{
Are we failing workers with symptoms suggestive of occupational asthma?
}

\section{* David Fishwicka, Lisa Bradshawa, Jo Daviesa, Mandy Henson a, Chris Stenton Sherw ood Burge ${ }^{c}$, Rob Niven ${ }^{d}$, Chris J Warburtone, David Hendrick ${ }^{b}$, Trevor Rogers', Roger Raw bone', Andrew D Currana}

\footnotetext{
${ }^{a}$ Medical Unit, Health and Safety Laboratory, Harpur Hill, Buxton, UK

${ }^{b}$ Royal Victoria Infirmary, Newcastle upon Tyne, UK

Chest Clinic, Birmingham Heartlands Hospital, Birmingham, UK

'North West Lung Centre, Wythenshawe Hospital, Manchester, UK

e Aintree Chest Centre, University Hospital, Aintree, Liverpool, UK

Doncaster Royal Infirmary, Doncaster, South Yorkshire, UK

${ }^{g}$ Health and Safety Executive, UK
}

Received 6th February 2007; accepted 8th June 2007

\begin{abstract}
Aims: To assess the route to secondary care for patients with possible occupational asthma, and to document the duration of workrelated symptoms and referral times.

Methods: Consecutive patients with suspected occupational asthma were recruited to a case series from six secondary care clinics with an interest in occupational asthma. Semi-structured interviews were performed and hospital case notes were reviewed to summarise relevant investigations and diagnosis.

Results: 97 patients were recruited, with a mean age of 44.2 years (range 24-64), 51 of whom (53\%) had occupational asthma confirmed as a diagnosis. Most (96\%) had consulted their general practitioner (GP) at least once with work-related respiratory symptoms, although these had been present for a mean of 44.6 months (range 0-320 months) on presentation to secondary care. Patients experienced a mean delay for assessment in secondary care of 4 years (range 1-27 years) following presentation in primary care.

Conclusions: Significant diagnostic delay currently occurs for patients with occupational asthma in the UK.

(C) 2007 General Practice Airways Group. All rights reserved.

D Fishwick, et al. Prim Care Resp J 2007; 16(5): 304-310.

doi:10.3132/pcrj.2007.00064
\end{abstract}

Keyw ords occupational asthma, referral, health and safety, investigation

\section{Introduction}

Occupational asthma remains a common occupational disease in the UK, with an estimated 3000 new cases per year. ${ }^{1}$ As approximately one in 10 cases of adult onset asthma is caused by occupational exposures, ${ }^{2}$ the cost to the UK is considerable. In 2000, the UK Health and Safety Executive estimated that $\mathrm{f1.1}$ billion is spent on this condition over each decade. Occupational asthma causes not only considerable personal hardship, ${ }^{3,4}$ but recent work suggests that the majority of the associated cost is borne by the individual worker and Government, not by employers. ${ }^{5}$ This is a tragic state of affairs, since occupational asthma is largely preventable.

Recent British Occupational Health Research Foundation (BOHRF) guidelines on occupational asthma, ${ }^{6}$ developed following extensive literature and evidence review, emphasise that early case identification is the key to improving prognosis; it states that, "occupational asthma should be considered in all workers with symptoms of airflow

\footnotetext{
* Corresponding author: Reader in Respiratory Medicine, Respiratory Function Unit, A Floor, Royal Hallamshire Hospital, Glossop Road, Sheffield, S10 2JF, UK. Tel: +44 (0)1142713631 Fax: +44 (0)1142711836 E-mail: d.fishwick@sheffield.ac.uk
} 
limitation". Specialist referral for all patients with suspected occupational asthma has been recommended in all editions of asthma guidelines from the British Thoracic Society. ${ }^{6}$

Whilst early detection may be achievable under certain circumstances in the workplace, case identification in primary care poses many specific problems. ${ }^{7}$ In order to detect cases of occupational asthma early it is important for all health care workers who are regularly in contact with working populations to remain vigilant to features of asthma and rhinitis that may suggest an occupational cause.

We were interested in the route of referral to secondary care for workers with suspected occupational asthma, and the delays encountered during this process. This paper presents the findings of a multi-centre study which had two main aims: first, to document worker's attitudes to, and perceptions of, the workplace and healthcare input, (reported elsewhere ${ }^{8}$ ) and second, to document the route and nature of referral to secondary care for further assessment. The second aim is the subject of this paper, and the method was designed specifically to investigate the diagnostic process adopted for workers with possible occupational asthma who were referred to secondary care for further investigation and diagnostic opinion.

\section{Methods}

Over a six-month period, patients were recruited from one of six secondary care centres in the UK with a clinical interest in occupational asthma. In order to be eligible for inclusion in the study all patients required mention in the referral letter of a possible diagnosis of occupational asthma. In addition, patients who were thought at the first outpatient attendance to have work-related respiratory problems were eligible for inclusion, even if the original referral letter had not suggested this diagnosis. Work-relatedness of symptoms in this context implied that asthma symptoms were worse at work, or better on rest days. The presence of such symptoms could signify either a diagnosis of occupational asthma or aggravation of non-occupational asthma in the workplace. There were no specific exclusion criteria.

Two months following inclusion in the case series, a semistructured telephone interview was carried out between one of two researchers (JD and $L M B$ ) and the study patient. The telephone survey asked about a variety of personal demographic details, symptoms and their work-relatedness, and workplace factors. The latter included details of work processes, likely exposures, access to occupational and nonoccupational medical services - including primary care providers, and attitudes to the workplace. All information was recorded on a semi-structured proforma (the main questions from which are shown in Appendix 1 at www.thepcrj.org) during the interview, and details of access to (and the timing of) primary care input was recorded in relation to the onset of work-related respiratory symptoms. A shorter version of the telephone interview was repeated approximately one year after the initial interview, again using a semi-structured format.

Following the second telephone interview, one of three researchers ( $\mathrm{LMB}, \mathrm{MH}$ and JD) visited each secondary care site and transcribed each original set of case notes into a third study proforma, focusing on diagnostic tests and clinical outcomes in addition to reported symptoms and worksite details. The results of serial peak expiratory flow (PEF) recordings carried out using OASYS 2 (Occupational Asthma SYStem ${ }^{9}$ ), challenge testing, and immunology investigations, were recorded in detail. It was also noted whether each case had been reported to the Surveillance of Work-Related and Occupational Respiratory Disease register (SWORD). A "final" diagnosis was recorded where available, allowing comparison between the diagnosis understood to be correct by the patient and that confirmed by the respiratory physician.

\section{Data analysis}

All data collected were entered into an SPSS for Windows (version 12.0.1) database. Differences between means were assessed using a student's test, and differences in proportions using a Chi squared test or Fishers Exact test. Underlying normality of the data was tested using SPSS normality testing and skewness statistic. Any non-normal data were log transformed prior to analysis and statistical significance was accepted at the 5\% level.

\section{Ethics approval}

The study was approved by the local multicentre research ethics committee and all individuals gave written informed consent to participate.

\section{Results}

One hundred subjects with potential occupational asthma were recruited into the study and data were obtained from 97 completed interviews - one subject withdrew prior to interview and two subjects became untraceable between recruitment and interview. The study subjects' mean age was 44.2 years (range 24-64); 73 were male (75\%) and 51 of these $(53 \%)$ were thought to have occupational asthma following their first visit in secondary care. No two workers came from the same workplace.

The majority of patients (59\%) were referred directly from primary care to the secondary care centre for assessment of possible occupational lung disease, although other routes of referral were noted. The remaining patients were referred by occupational health physicians (22\%), another secondary care facility (10\%), solicitors (9\%), Trades Unions (8\%), another secondary care physician following a hospital admission with acute severe asthma (8\%), and an occupational health nurse (1\%). Certain workers were referred by more than one route. 
D Fishwick et al.

Occupational health provision for these workers prior to referral was variable. For example, whilst most (73 workers) had access to some form of occupational health provision in the workplace, only 47 of these 73 were provided with a full-time service. Of these 73 workers, 61 had access to an occupational health nurse, and 37 received such input at the worksite.

Health surveillance was not universally offered to all workers. Whilst 60 workers had been enrolled in some form of health surveillance, only eight appeared to undergo regular annual assessment. Twenty-seven of the 60 undergoing health surveillance stated that health surveillance was offered "when necessary". Only two workers reported pre-employment assessment of their respiratory health.
Workers were subsequently divided into those exposed to the asthmagens or tasks listed by HSE as being common causes of occupational asthma. ${ }^{10} \mathrm{~A}$ list of selected recognised causes of occupational asthma is found in Appendix 2 at www.thepcrj.org. Fifty of the 97 were exposed to at least one of these agents. There was no significant difference between health surveillance provision between those with such workplace exposure (64\% with health surveillance) and those not exposed to any of these agents (59.6\%).

Most individuals had presented to their primary care physician with symptoms of asthma or symptoms suggestive of allergic involvement of the upper airway or mucous membranes. Work-related shortness of breath was the most

Figure 1. Distribution of individual duration of work related respiratory symptoms on first presentation to secondary care.

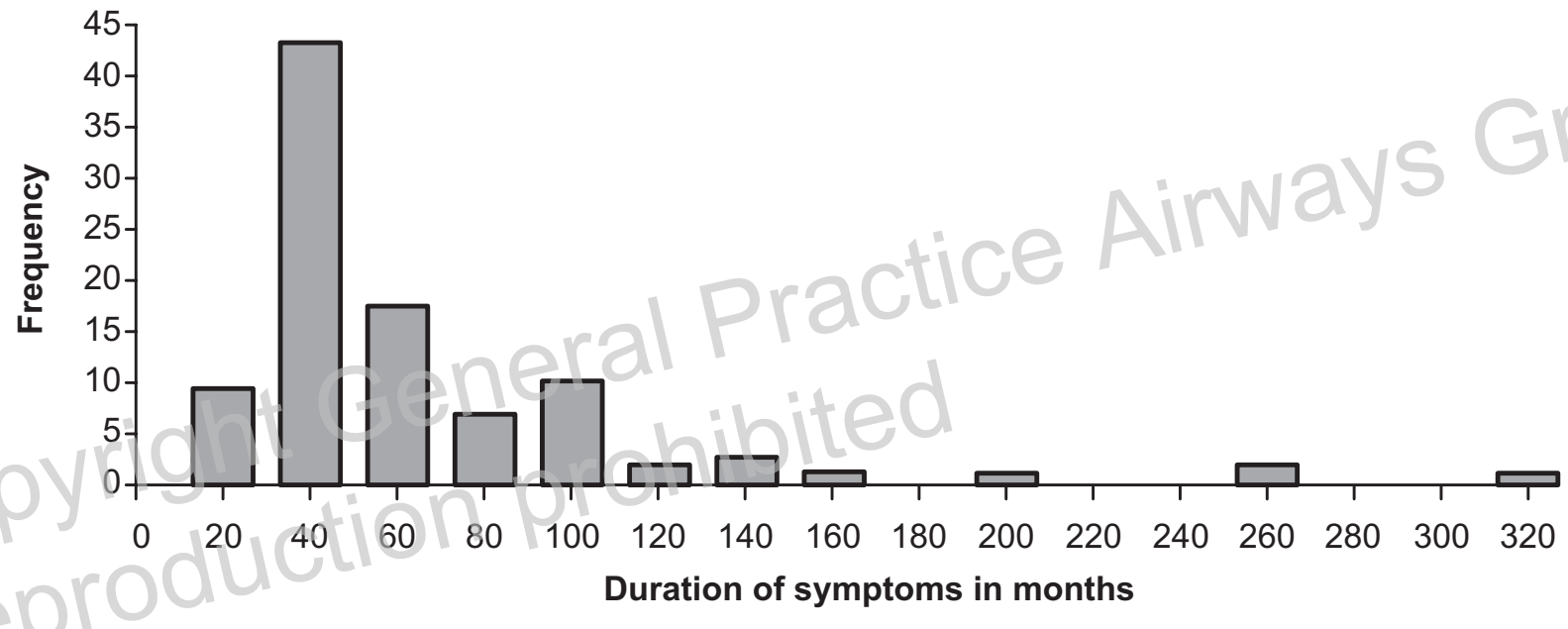

Figure 2. Number of years betw een first primary care contact concerning work related symptoms and secondary care assessment.

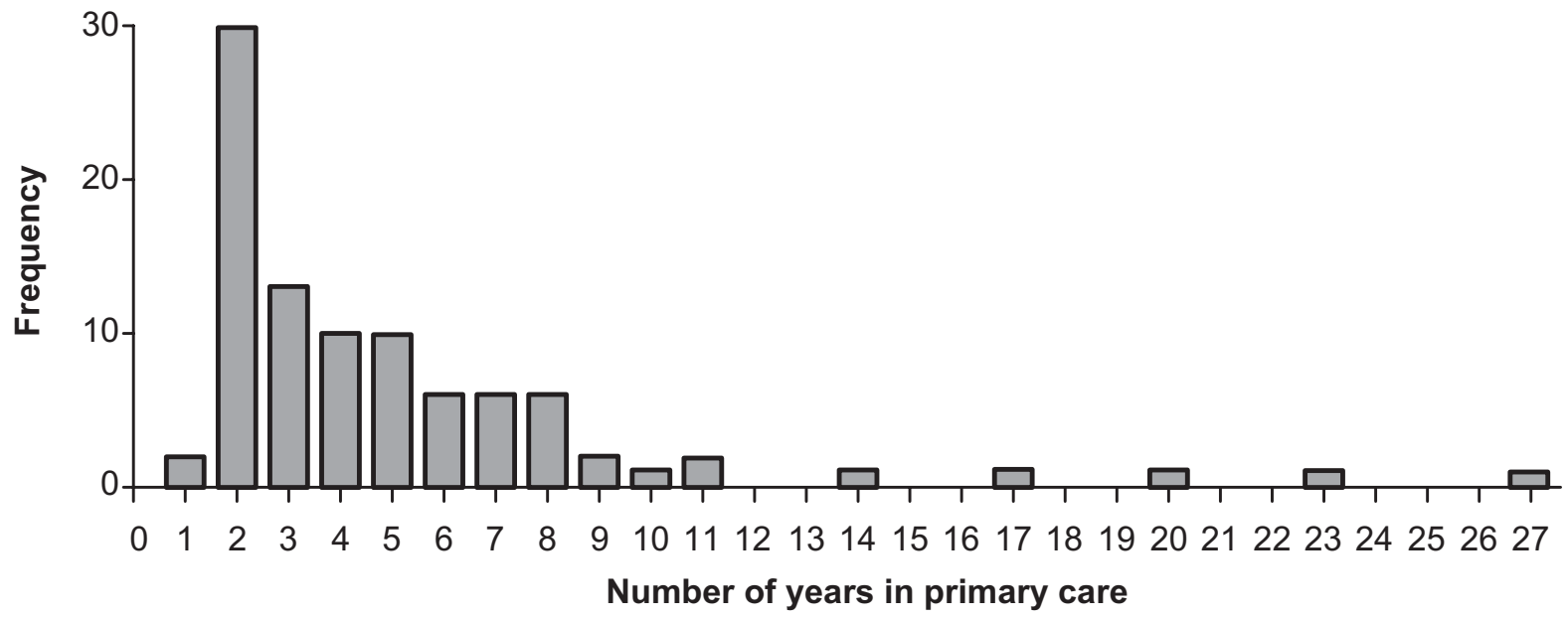


common work-related symptom (76\%) followed by chest tightness $(62 \%)$, wheeze (57\%), cough $(56 \%)$, nasal symptoms (31\%) and ocular "irritation" (24\%). In general, these symptoms were perceived to be work-related, since they were reported to be worse at work $(94 \%)$ or improved on rest days and holidays ( $81 \%)$. The vast majority of these workers $(96 \%)$ had initially attended primary care at least once for advice about their symptoms. Of those seeing their primary care provider, $50 \%$ had consulted on more than five occasions with the same complaints prior to secondary care referral. Only $58 \%$ of all workers in the study had contacted their appropriate occupational health professional for advice.

Figure 1 shows the distribution of individual duration of work-related respiratory symptoms on first presentation to secondary care. The mean symptom duration was 44.6 months (median 24 months, range 1-324). The distribution was significantly skewed from normal.

Figure 2 illustrates the number of years between first contacting a primary care provider about these symptoms and being seen in secondary care; the mean duration was 4 years (median of 3 years). The distribution was again significantly skewed from normal.

Whilst $33 \%$ of workers were seen in secondary care within one year of contacting their primary care physicians, eight workers waited more than 10 years between first contacting their primary care physician and referral for assessment, and of these eight, two workers waited more than 20 years for referral to secondary care.

At the time of the first interview, approximately half of all workers had been given a diagnosis of occupational asthma. One diagnosis had been made in primary care, three diagnoses had been made by an occupational health physician, and the rest of the diagnoses had been made in secondary care. There were no significant differences in mean duration of work-related respiratory symptoms ( $p=0.61$ following log transformation) or primary care contact ( $p=0.77$ following log transformation) between those with or without a subsequently confirmed diagnosis of occupational asthma.

On case notes review, 25 (60\%) of confirmed occupational asthma cases had been reported to SWORD (the Surveillance of Work related Occupational Respiratory Disease reporting scheme) and 14 (42\%) of the 33 with an unsure diagnosis had also been reported as a case of occupational asthma.

Ninety-two individuals (95\%) were successfully contacted for the second interview 12 months later, and $41 \%$ were still working in the same occupation. Adaptations in the workplace had occurred in $53 \%$ of worksites where workers continued in the same job, in comparison to $37 \%$ of workplaces where workers were not in the same job at a year $(p=0.2)$.

Case notes review also allowed comparison between the eventual diagnosis by the patient, diagnosis arrived at by the physician, and the results of any relevant secondary carebased investigations. Ninety-two workers (97\%) had undergone lung function testing, $76(80 \%)$ skin prick testing, 72 (76\%) non-specific bronchial challenge, 60 (63\%) serial PEF measurements using the OASYS 2 system, seven had specific bronchial challenge testing (7\%), and seven (7\%) had a workplace challenge.

Table 1 illustrates the levels of agreement between patient and hospital physician concerning diagnosis. Approximately one third of individuals felt they had occupational asthma when the physician had not yet made a definite diagnosis and only approximately three quarters of workers fully understood that a diagnosis of occupational asthma had been confirmed.

Table 2 shows the results of serial PEF assessment (OASYS II system ${ }^{11}$ most commonly used) in those suspected of having occupational asthma, stratified by the final diagnosis. Those given a final diagnosis of occupational asthma were not

\begin{tabular}{lcc}
$\begin{array}{l}\text { Table 1. Physician and patient agreement about final } \\
\text { diagnosis reached. }\end{array}$ & & $\begin{array}{c}\text { Patients believe } \\
\text { they have } \\
\text { occupational asthma } \\
\mathrm{n}(\%)\end{array}$ \\
$\begin{array}{l}\text { Respiratory } \\
\text { physician } \\
\text { diagnosis }\end{array}$ & 33 & $12(36)$ \\
\hline Don't know & 42 & $31(74)$ \\
Occupational asthma & 2 & $1(50)$ \\
Acute irritant induced asthma* & 12 & $1(8)$ \\
Asthma & 2 & - \\
COPD & 3 & - \\
Other & & - \\
\hline
\end{tabular}

*Formerly termed RADS

\section{Table 2. Serial OASYS II style PEF assessment and the} eventual diagnosis.

\begin{tabular}{|c|c|c|c|c|}
\hline $\begin{array}{l}\text { Respiratory } \\
\text { physician } \\
\text { diagnosis }\end{array}$ & $\mathrm{n}$ & $\begin{array}{c}\text { OASYS II } \\
\text { +ve } \\
n(\%)\end{array}$ & $\begin{array}{c}\text { OASYS II } \\
\text {-ve } \\
\text { n (\%) }\end{array}$ & $\begin{array}{c}\text { OASYSII } \\
\text { not done } \\
\text { n (\%) }\end{array}$ \\
\hline Don't know & 33 & $3(9)$ & $12(36)$ & $18(55)$ \\
\hline Occupational asthma & 42 & $13(31)$ & $15(36)$ & $14(33)$ \\
\hline \multicolumn{5}{|l|}{ Acute irritant } \\
\hline induced asthma* & 2 & $0(0)$ & $1(50)$ & $1(50)$ \\
\hline Asthma & 12 & $2(17)$ & $5(41.5)$ & $5(41.5)$ \\
\hline COPD & 2 & $1(50)$ & $0(0)$ & $1(50)$ \\
\hline Other & 3 & $1(33.3)$ & $1(33.3)$ & $1(33.3)$ \\
\hline
\end{tabular}

*Formerly termed RADS 
consistently investigated using this technique. In fact, approximately one-third of those with a final diagnosis of occupational asthma had a serial PEF chart with a negative work effect index (regarded as evidence against occupational asthma).

\section{Discussion}

This study is the first to address the diagnostic process for possible occupational asthma in the UK, as well as associated worker perceptions. The latter have been previously reported. ${ }^{8}$

Many workers with potential occupational asthma experienced significant delay in obtaining appropriate assessment. This was evidenced by the generally long duration of work-related respiratory symptoms at presentation in secondary care and the duration of primary care consultation for these symptoms prior to referral. These delays presumably allowed certain workers at risk in the work environment to continue to be harmfully exposed. Whilst many workers were dealt with relatively efficiently, eight workers waited more than 10 years prior to referral for further investigation.

There are relatively few data internationally with which to compare, although recent Canadian data ${ }^{12}$ reported similar delays in patients eventually referred to secondary care for further assessment of occupational asthma.

Half of all patients had attended their primary care provider on more than five occasions prior to specialist referral, although half reported fewer consultations. Despite referrals to secondary care being made from varying routes, it is evident that virtually all patients sought advice at least once from primary care, suggesting that primary care is well placed to identify early cases of occupational asthma.

With regard to appropriate investigations being ordered prior to secondary care referral, only one worker had a diagnosis of occupational asthma confirmed in primary care, and none were significantly investigated prior to secondary care referral. The design of this study does not allow further comment on how the single primary care diagnosis was made. It was also evident that a significant proportion of workers had no access to an occupational health service, a problem previously described in both non-health care ${ }^{13,14}$ and health care settings. ${ }^{15}$ These workers presumably relied on primary care for such input, consulting health care workers with little or no knowledge of their workplace processes and potential inhaled exposures. This issue remains currently unresolved in the UK, although it is clear that whilst it is possible to configure such input in primary care, ${ }^{16}$ lack of time during the consultation and lack of appropriate training may pose significant problems. ${ }^{17}$ Whilst in theory increasing knowledge levels are likely to be the key to successful change, this may be difficult to achieve in practice taking into account the large number of primary care-based health care workers.
As primary care may be the only site of advice for many such workers, investment in the education infrastructure related to the primary care Quality and Outcomes Framework (QOF) is perhaps one potential solution.

The use of diagnostic tests in this study, such as serial PEF measurements and measures of bronchial responsiveness, was confined to secondary care. Whilst the ability to perform these tests is regarded as an essential requirement for the assessment of such workers, ${ }^{18}$ it is clear that the work effect index alone was not used to reach a final diagnosis. Many patients with negative OASYS charts were confirmed as having occupational asthma. This paradox may be partially explained by variation between expert raters when assessing PEF data, ${ }^{19}$ and may also represent the current lack of clear diagnostic consensus generally between expert centres ${ }^{20}$ although the sensitivity and specificity of OASYS analysis of serial PEF measurements depends on data quality. For records of adequate quality, the specificity of a positive PEF chart is high (around 94\%), but the sensitivity using the work effect score generated by OASYS 2 software alone is $70 \% .21,22$ It is therefore reasonable for an expert to make a diagnosis of occupational asthma in a record with a non-diagnostic score. Negative PEF charts (not showing a work effect) may also reflect in part reduction in exposure to asthmagen, or workplace adaptation that has already occurred prior to secondary care assessment.

Once a diagnosis of occupational asthma had been confirmed or excluded, the patient understanding of this decision was variable. The reasons for this are unclear, although effective communication with asthma patients during a consultation is the key to ensuring best understanding of a proposed diagnosis. ${ }^{23}$ Consultations with patients with possible occupational asthma should be longer than standard asthma consultations. Cases are often complex, because an established diagnosis of occupational asthma may have personal, social, financial and legal implications. In this context, the documented failure of patients to accept and understand the diagnosis given may not only reflect communication difficulties but also the complex interaction between personal perceptions of ill health within the workplace dynamics. ${ }^{8}$

This study has clear shortcomings. Recall bias may have affected the patients' ability to report the onset and various assessments of their respiratory symptoms by health care workers, and may influence the interpretation of these findings. It was also not possible to cross reference information supplied by patients to their occupational health and primary care records within this study design. Whilst recall may be inaccurate, there may be other reasons why workers with potential occupational asthma may not accurately report disease progression, including concern about job loss. For 
example, previous work has shown that workers may not be accurate when completing health surveillance questionnaires. ${ }^{24}$ Qualitative data from this current study also suggests that workers with possible occupational asthma have complex and largely negative attitudes to and perceptions of the workplace, ${ }^{8}$ factors that are also likely to influence reporting of work related symptoms.

How can the current situation be improved in order to lessen delays and identify cases of occupational asthma earlier? As this study was carried out prior to the dissemination of the key features of the BOHRF guidelines into primary care, the clinical practice seen in this study will reflect the pre-existing knowledge of each practitioner and pre-existing awareness of any HSE-based initiative (for example, MS25, medical aspects of occupational asthma ${ }^{25}$ ) as well as the BTS/SIGN asthma guidelines. It is hoped that the recent dissemination of the BOHRF guidance into primary care will improve overall awareness of the link between asthma and work.

The BOHRF guideline stresses the importance of early assessment of workers with work-related respiratory symptoms, as there is good evidence that early removal of affected workers from exposure improves the overall prognosis. Subsequent work also suggests that decline in the forced expiratory volume in one second $\left(\mathrm{FEV}_{1}\right)$ is more marked in those continually exposed in the workplace as compared to those no longer harmfully exposed. ${ }^{26}$ These guidelines also emphasise the need to enquire about current and previous work in all patients with airways disease, and in particular the nature of the agents with which the patient has worked. Job title itself is a marker of risk for occupational asthma, ${ }^{27}$ and this fact could easily be exploited further in primary care when identifying at-risk groups of workers, or at-risk groups of patients with asthma. Work-relatedness of respiratory symptoms should be documented (notably rest day improvement), and following commencement of serial PEF monitoring, early referral should be made to a specialist with an interest in occupational asthma.

Whilst guidance may improve overall awareness of occupational respiratory issues within primary and secondary care, it is likely that improved communication and specific training will also be required to sustain improved practice. Examples could include improved written or verbal communication between all relevant parties to allow primary care a greater working knowledge of local workplaces and likely exposures, and potentially allowing confidentiality issues to be used in a productive manner to reduce risk to all harmfully exposed workers once a sentinel diagnosis is confirmed. From the worker's perspective, health risk communication should be focused - either as part of, or separately from, a health surveillance programme - on relevant symptoms that may signify early occupational asthma, and what action to take should these symptoms develop. In time, integrating such information into an asthma self-management plan for those with asthma would seem sensible. An integrated care pathway could also be developed to guide healthcare workers through the essential steps in the diagnostic process.

In summary, this study has assessed the diagnostic process for occupational asthma in the UK, and has documented significant delays. A wide-ranging approach, including guidance dissemination, training and improved communication is probably required to improve overall management of this condition.

\section{Acknow ledgements and funding declaration}

The authors wish to thank all the workers and patients who participated in this study, and the Health and Safety Executive of the United Kingdom who provided funding.

\section{Conflict of interest declaration}

There were no conflicts of interest for the authors in the preparation of this paper.

\section{References}

1. Health and Safety Executive of the United Kingdom website, asthma homepage, 2006. http://www.hse.gov.uk/asthma/index.htm.

2. Blanc PD, Toren K. How much adult asthma can be attributed to occupational factors? Am J Med 1999;107(6):580-7

3. Moscato G, Dellabianca A, Perfetti L, et al. Occupational asthma: a longitudinal study on the clinical and socio-economic outcome after diagnosis. Chest 1999; 115:249-56

4. Ross DJ, McDonald JC. Health and employment after a diagnosis of occupational asthma: a descriptive study. Occup Med 1998;48:219-25.

5. Health and Safety Executive website. http://www.hse.gov.uk/research/ rrpdf/rr474.pdf (last accessed June 2007).

6. British Guideline on the Management of Asthma. Thorax 2003;58 (Supplement 1) and http://www.brit-thoracic.org.uk/Guidelinessince\%201997_asthma_html. (last accessed June 2007).

7. Levy ML, Nicholson PJ. Occupational asthma case finding: a role for primary care. Br J Gen Pract 2004;54(507):731-3.

8. Bradshaw LM, Barber CM, Davies J, Curran AD, Fishwick D. Work-related asthma symptoms and attitudes to the workplace. Occup Med (Lond) 2007:57:30-35.

9. Burge PS, Pantin CF, Newton DT, et al. Development of an expert system for the interpretation of serial peak expiratory flow measurements in the diagnosis of occupational asthma. Midlands Thoracic Society Research Group. Occup Environ Med 1999;56(11):758-64.

10. Health surveillance for occupational asthma, Control guidance sheet 402 . HSE books and at http://www.coshh-essentials.org.uk/assets/live/G402.pdf. (last accessed June 2007).

11. Gannon PF, Newton DT, Belcher J, Pantin CF, Burge PS. Development of OASYS2: a system for the analysis of serial measurement of peak expiratory flow in workers with suspected occupational asthma. Thorax 1996;51(5):484-9.

12. Poonai N, van Diepen S, Bharatha A, Manduch M, Deklaj T, Tarlo SM. Barriers to diagnosis of occupational asthma in Ontario. Can J Public Health 2005;96(3):230-3.

13. Bradshaw LM, Curran AD, Eskin F, Fishwick D. Provision and perception of occupational health in small and medium-sized enterprises in Sheffield, UK. Occup Med 2001; 51(1):39-44.

14. Kinoulty $\mathrm{M}$, Williams $\mathrm{N}$. Occupational health provision and health surveillance 
D Fishwick et al.

in the semiconductor industry. Occup Med (Lond) 2006;56(2):100-01.

15. Ujah EU, Bradshaw L, Fishwick D, Curran AD. An evaluation of occupational health services within the NHS in London. Occup Med (Lond) 2004;54(3):159-64.

16. Harrison J, Harrison CE. Developing a model for occupational health provision in primary care. Int J Occup Med Environ Health 2002;15(2):185-92.

17. Elms J, O'Hara R, Pickvance $S$, et al. The perceptions of occupational health in primary care. Occup Med 2005;55(7):523-7.

18. Francis H, Prys-Picard C, Fishwick D, et al. Defining and investigating occupational asthma: a consensus approach. Occup Environ Med 2007;6(6):361-5. Epub 2006 Nov 27.

19. Baldwin DR, Gannon P, Bright $P$, et al. Interpretation of occupational peak flow records: level of agreement between expert clinicians and OASYS 2. Thorax 2002;57(10):860-4.

20. Fishwick D, Bradshaw LM, Henson M, et al. Occupational Asthma. An assessment of diagnostic agreement between physicians. Occup Environ Med 2007;64(3):185-90. Epub 2006 Nov 9.

21. Anees W, Gannon PF, Huggins V, Pantin CFA, Burge PS. Effect of peak expiratory flow data quality on diagnostic sensitivity and specificity in occupational asthma. Eur Respir J 2004;23:730-4.

22. Gannon PFG, Newton DT, Belcher J, Pantin CFA, Burge PS. Development of OASYS-2: a system for the analysis of serial measurements of peak expiratory flow in workers with suspected occupational asthma. Thorax 1996;51:484-9.

23. Partridge MR. The asthma consultation: what is important? Curr Med Res Opin 2005;21 Suppl 4:S11-S17.

24. Gordon SB, Curran AD, Murphy J, Sillitoe C, Lee G, Wiley K, Morice AH. Screening questionnaires for bakers' asthma--are they worth the effort? Occup Med 1997;47(6):361-6.

25. MS25. Medical Aspects of Occupational Asthma. HMSO, HSE books. 2nd Edition, 1998. ISBN 0717615472.

26. Anees $\mathrm{W}$, Moore V, Burge PS. FEV1 decline in occupational asthma. Thorax 2006;61(9):751-5

27. Kennedy SM, Le Moual N, Choudat D, Kauffmann F. Development of an asthma specific job exposure matrix and its application in the epidemiological study of genetics and environment in asthma (EGEA). Occ Environ Med 2000;57(9):635-41.

\section{Available online at http://w ww.thepcrj.org}


Appendix 1. Proforma used for semi structured telephone questionnaire.

\section{Demographics \\ 1. Gender \\ 2. Age \\ 3. Date of Birth}

\section{Workplace Description}

4. Job title

5. How many other employees (if known)?

6. Your Main tasks

7. Potential or known exposures

8. Do you wear any Protective Equipment (PPE)? yes $\square \quad$ no $\square$ if yes what?

9. Potential Hazards / Hazards

10. Have you received any hazard training yes $\square \quad$ no $\square$ if yes what?

\section{Health and Safety}

11. Does the company have a health \& safety officer yes $\square \quad$ no $\square$

12. Does the company have an occupational health service

yes $\square \quad$ no $\square$ if yes who provides the service and what does it consist of?

13. What health surveillance is carried out (if any)

14. If health surveillance is carried how often is this carried out?

\section{About them}

15. What are your current symptoms?

16. How long have you had these symptoms?

17. Are they work related

18. Have you consulted your GP about these symptoms yes $\square \quad$ no $\square$ if yes how many times?
19. When did you first consult your GP?

20. Have you consulted your Occupational Health department (if applicable)

yes $\square \quad$ no $\square$ if yes how many times?

21. Have you been referred to a hospital physician regarding these symptoms

yes $\square \quad$ no $\square$ if yes how many times have you seen them?

22. Have you been given a diagnosis?

yes $\square \quad$ no $\square$ if yes what have you been told?

23. Who diagnosed this?

24. Have you required any tests to confirm this diagnosis

yes $\square \quad$ no $\square$ if yes what were the tests

25. Are you still in the job where your symptoms first began

yes $\square \quad$ no $\square$

26. Are you aware of any risk assessments being carried out in your workplace?

yes $\square \quad$ no $\square$

27. Are you aware of any COSHH assessments being carried out in your workplace?

yes $\square \quad$ no $\square$

28. Are you aware of any inspection of your company by HSE or the City Council Environmental Health Dept. yes $\square \quad$ no $\square$

\section{Other Comments}

Appendix 2. Selected recognised causes of occupational asthma.

\begin{tabular}{l|l|l} 
Alpha amylases & Egg protein & Persulphates \\
Azodicarbonide & Ethylenediamine & Piperazine \\
Bromelains & Fish proteins & Psyllium \\
Carmine & Flour dust & Pthalic anhydride \\
Castor bean dust & Glutaraldehyde & Rosin-based solder fume \\
Cephalosporins & Henna & Some Hardwood dusts \\
Chloramine-T & Isocyanates & Some reactive dyes \\
Chloroplatinates and other & Ispaghula & Some softwood dusts \\
Halogenoplatinates & Laboratory animal excreta/secreta & Soybean dust \\
Chromium (VI) compounds & Latex & Spyramycin \\
Cobalt (metal and compounds) & Maleic anhydride & Storage mites \\
Cockroah material & Methyl-terahydropthalic anhydride & Subtilisins \\
Coffee bean dust & Tetrachloropthalic anhydride \\
Cow epithelium/urine & Trimellitic anhydride \\
Crustacean proteins & Opiates & \\
Diazonium salts & Papain & \\
\hline
\end{tabular}

